Revista Iberoamericana, Vol. LXXIII, Núm. 218, enero-marzo 2007, 165-177

\title{
LA VOZ IMPENITENTE DE LA “SICARESCA” COLOMBIANA
}

\author{
POR \\ María Fernanda Lander \\ Washington University in St. Louis
}

El 2 de diciembre de 1993 muere en Medellín, en manos de los cuerpos de seguridad del Estado colombiano, el internacionalmente conocido capo de la droga Pablo Escobar Gaviria. Terminaban para él dieciséis meses de huidas, y se pensó que comenzaba para Colombia un periodo de recuperación frente a las heridas dejadas por la guerra que desataron los narcotraficantes para evitar la extradición a los Estados Unidos. ${ }^{1}$ Una de las revistas más populares de Bogotá, Semana, en su nota editorial resumió la marca que dejara “El Patrón” en la historia contemporánea del país con las siguientes palabras:

[Pablo Escobar] Transformó el lenguaje, la cultura, la fisonomía y la economía de Medellín y del país. Antes de Pablo Escobar los colombianos no conocían la palabra sicario. Antes de Pablo Escobar, Medellín era considerada un paraíso. Antes de Pablo Escobar el mundo conocía a Colombia como la Tierra del Café. Y antes de Pablo Escobar, nadie pensaba que en Colombia pudiera explotar una bomba en un supermercado o en un avión en vuelo. Por cuenta de Pablo Escobar hay carros blindados en Colombia y las necesidades de seguridad modificaron la arquitectura. ("Fin de una tragedia")

\footnotetext{
${ }^{1}$ En 1979, Colombia y los Estados Unidos firmaron un acuerdo en el que se consideraba un crimen contra el país del norte el envío de drogas ilegales. Una de las exigencias del tratado era que los colombianos sobre quienes recayera la sospecha de tráfico de drogas, podían ser extraditados a los Estados Unidos para ser juzgados y, si se los hallaba culpables, encarcelados en ese país. Durante el periodo de gobierno de Belisario Betancourt (1982-1986), y por presiones del gobierno de los Estados Unidos, se da sanción al tratado de extradición. Los narcotraficantes en respuesta le declararon la guerra al gobierno. Fue César Gaviria, como presidente de Colombia (1990-1994), quien negoció un arreglo con los jefes de los principales carteles de la droga. El acuerdo requería que los traficantes confesaran todos sus crímenes y estuvieran listos a asumir largas sentencias de prisión. Sin embargo, estos no aceptaron la propuesta y se inició la feroz guerra con carrobombas y asesinatos de manos de sicarios. Dicha guerra fue justificada por los narcotraficantes con la famosa frase de Escobar: "Prefiero una tumba en Colombia que una celda en Estados Unidos". La lucha continuó hasta forzar al presidente Gaviria a que aceptara los términos de la rendición. Al final de las negociaciones, Pablo Escobar terminó en La Catedral, una “prisión” colombiana con incomparables lujos, desde jacuzzis, televisores y computadoras hasta campos de fútbol. Finalmente, Escobar se aburrió y escapó sólo para terminar baleado en los techos de Medellín. Para una visión general de lo que fue el apogeo y caída de la figura de Pablo Escobar véase el libro de Mark Bowden Killing Pablo. The Hunt for the World's Greatest Outlaw.
} 
La nota revela hasta qué punto la sociedad se reconoció víctima de la agudización de la batalla entre el gobierno y el narcotráfico que tuvo lugar a finales de la década de los ochenta y principios de los noventa. También resalta la proyección de un pasado de tonos idílicos con el que se identifica un sector de la sociedad ajeno al contexto de los cinturones de miseria que rodean la ciudad y que es, sin duda alguna, la mayoría del público lector de la revista. Y hablamos de idealización del pasado porque es imposible ignorar que difícilmente Medellín ha podido ser un paraíso para los que desde mucho antes de que se iniciara esa guerra han vivido bajo condiciones de pobreza extrema. Para los que habitan en las zonas marginales que bordean la ciudad, poco pudo, o puede importar, cómo se conoce a Colombia en el resto del mundo porque el aroma de la realidad que ellos enfrentan no es precisamente el del café. ${ }^{2}$ Tácitamente, el comentario de Semana deja en claro que, como en la mayoría de las metrópolis latinoamericanas, Medellín toma forma dependiendo de la posición geográfica del sujeto que la habita, y es esta condición la que impide singularizarla en términos de una única y determinada experiencia colectiva. Es esto lo que obliga a hablar, necesariamente, de dos ciudades, dueñas cada una de sus propios sistemas de sociabilidad, actitudes y expresiones culturales particulares y definitorias. ${ }^{3}$ Medellín y Medallo (el apodo de la ciudad que surge de las comunas) nombran esos dos universos que comparten el mismo punto geográfico en el mapa.

Por otra parte, lo peculiar de la nota editorial de la revista es que une discursivamente las dos realidades de la urbe en el momento en que reconoce que los miembros de ambos mundos le han dado a la palabra sicario recurrencia en el contexto cotidiano. Estar al tanto del término significó, para unos, abandonar la concepción del área urbana como el espacio aséptico al que protegen sólidas fronteras de clase; y para otros, la "profesión” capaz de brindar beneficios económicos con los cuales poder derrumbar tales fronteras. ${ }^{4}$ Innegablemente, para ambos grupos alternar con tal vocablo implicó aceptar las consecuencias de las imposiciones de una realidad económica que facilitó la promoción de la muerte como un insumo más.

El matar por dinero hiperboliza una implacable lógica de mercado que, desde la perspectiva que cuestiona el influjo del neoliberalismo económico en Latinoamérica, ve

\footnotetext{
${ }^{2}$ Para un acercamiento a la historia de los procesos políticos, económicos y sociales que han dado forma a la situación de marginalidad de las comunas de Medellín consúltense los trabajos de Alonso Salazar La génesis de los invisibles. Historias de la segunda fundación de Medellín (113-132), y la colección de ensayos En qué momento se jodió Medellín.

${ }^{3}$ En su análisis sobre la crisis de lo popular en Latinoamérica, Jean Franco define el sentido de “crisis" en relación con el consumo. Para ella, la crisis no tiene que ver con la productividad sino con la exhibición de símbolos de buen vivir (The Decline and Fall... 63). Ello bien podría considerarse como la práctica de la diferencia. Esta práctica llega incluso a precisar los términos en que las distintas expresiones culturales y los sistemas de sociabilidad se construyen. Para un análisis de la incidencia que la incapacidad de consumo tiene en relación con la violencia de los sicarios, véase el trabajo de Alexander Prieto Osorno Los sicarios de Medellín (29-39).

${ }^{4}$ Según señala Alexander Prieto Osorno, hoy en día la palabra sicario “dejó de ser el apelativo para señalar a los asesinos a sueldo. Tomó, en cambio, un nuevo significado. Se utiliza para referirse a la última generación de jóvenes en Medellín, cuya vida delictiva acabó con todos los conceptos establecidos que definen la criminalidad y rompió los récord de la delincuencia en el país” (161162).
} 
en el sujeto al consumidor y no al ciudadano (García Canclini 15-34). Así, y como consecuencia de los requerimientos económicos que establece el valor social del sujeto, una de las estrategias más efectivas de la que se sirvieron los narcotraficantes fue la contratación de jóvenes de las zonas marginales para quienes es más difícil cumplir con el imperativo de poseer determinados bienes de consumo -zapatos, jeans y camisetas de marcas específicas, entre otras cosas- como certificación de ciudadanía (Von der Walde 37). Del reconocimiento de esa realidad surge en Colombia el fenómeno literario que hoy se conoce como la "sicaresca”, 5 "género" que ya cuenta con un considerable corpus de novelas que permite comenzar a establecer sus rasgos característicos.

El juego semántico con el cual paródicamente se bautizó a ese grupo de textos, puede decirse que nace de dos puntos de contacto con la picaresca española del siglo xvi que, aunque generales, no dejan de ser procedentes. ${ }^{6}$ Primeramente, se trata de historias en las que la pobreza es el resorte que impulsa las acciones de los personajes. En el caso de las novelas colombianas, se trata de la exposición de la vida de carencias y miserias de jóvenes asesinos por contrato, y las peripecias por las que pasan para sobrevivir en el submundo del crimen. De tal manera, la conexión más obvia entre la sicaresca y la picaresca es la recreación de un personaje cuya juventud, inexperiencia, continuo movimiento y particular visión de la sociedad que lo relega, se convierten en las características que definen al nuevo antihéroe.

Otro punto de contacto es lo que, con respecto de la picaresca española, Peter Dunn ha señalado como la creación de un mundo imaginativamente tolerable que incorpora una intolerable realidad: la violencia de la vida urbana (303). En consecuencia, y aunque se trate claramente de productos de violencias históricas distintas, en ambos géneros los personajes adquieren la condición metonímica del sujeto urbano socialmente marginado. Sin embargo, la particularidad de la sicaresca se halla en la representación explícita de la doble percepción que define el perfil del espacio citadino en el que transcurre la vida diaria de los personajes.

En la construcción del sicario, la experiencia traumática de la violencia que ellos encarnan se construye a partir de la índole dual que de la ciudad y la ciudadanía mantienen los diferentes sectores de la sociedad. Dicha dualidad se expresa en la construcción de los discursos que predefinen las condiciones de víctimas (supuestamente la de quienes pertenecen al área urbana legitimada) y la de victimarios (hipotéticamente los residentes

\footnotetext{
${ }^{5} \mathrm{~A}$ parte de las novelas que se analizan en este estudio, otras que figuran como representantes del nuevo "género" y que han dado de qué hablar a críticos y lectores son: Hijos de la nieve (2000) de José Libardo Porras, y Comandante Paraíso (2002) de Gustavo Álvarez Gardeazábal. La novela Delirio de Laura Restrepo, ganadora del premio Alfaguara de Novela 2004, es incluida por su propia autora dentro de este "género" ("Premio Alfaguara...”). El aporte de Restrepo es, sin duda alguna, el del humor. Por otra parte, el cine también se ha aprovechado del motivo del sicario y las variantes del tema del narcotráfico. Ejemplo de ello es el documental ficción Rodrigo D: no futuro (1990) y La vendedora de rosas (1993) de Víctor Gaviria así como también la película Sicario (1994) del venezolano José Novoa.

${ }^{6}$ A Héctor Abad Facciolince, novelista colombiano retractor de la sicaresca, es a quien algunos le han atribuido la invención del término. Sin embargo, se puede decir que debido a la popularidad de la expresión, buscar sus orígenes implicaría abordar una empresa filológica de amplia envergadura, y ése no es el fin de nuestro trabajo.
} 
de las comunas) que se adjudican los habitantes de la ciudad. La vuelta de tuerca que ofrece la "sicaresca", es que busca la empatía de un lector implícito a quien se asume como víctima de la violencia por pensarse un elemento ajeno a los cinturones de miseria, pero que el correr de las lecturas, poco a poco, lo descubre como victimario. Esto es lo que Erna Von der Walde ha calificado como la "lógica perversa" de estas novelas, pues es lo que atrapa al lector real en el marasmo de la violencia (37). Sin embargo, es importante apuntar que la tensión entre víctima y criminal no se ofrece desde un ingenuo sentido moralista, sino que responde a la puesta en crisis de terminologías que en el proceso de buscar explicación a las raíces de la violencia han ido perdiendo su función diferencial. Dicho de otro modo, la "sicaresca" juega con el agotamiento de significados sobre los cuales los discursos tanto morales como legales sostienen la acusación o el indulto. Así, lo que principalmente resalta en estos textos es el hecho de que los parámetros sobre los cuales se sostienen ambos juicios, no son descodificados de la misma manera por los personajes que representan las dos realidades que conforman la ciudad. En este sentido, y apoyadas en la presentación de un mundo y sus modos de funcionamiento inédito para el lector, estas novelas intentan aprehender la lógica que alimenta al crimen para, a partir de allí, ofrecer una nueva comprensión de las nociones de víctimas y victimarios. La "sicaresca”, al representar el diálogo entre los mundos divorciados que dan forma a la ciudad, construye un precario espacio de encuentro que impele al lector a reconocerse en lo desconocido y, al hacerlo, descubrir que los conceptos de víctima y victimario pierden su valor semántico tradicional y se tornan indistinguibles.

Tres de las novelas más destacadas dentro del conjunto de textos que explora la vida de los sicarios, juegan con la dinámica dual del espacio urbano a través de la representación de unos criminales cuya actitud impertérrita se ofrece, a la misma vez, como el ataque final y como juicio acusador a la sociedad que los produjo. Nos referimos a la ineludible Virgen de los sicarios (1994) de Fernando Vallejo, Rosario Tijeras (1999) de Jorge Franco y Sangre ajena (2002) de Arturo Alape. Estas obras, desde perspectivas narrativas distintas coinciden en la recreación del sujeto criminal inmutable frente al daño causado. La distinción entre esos dos mundos a los cuales pertenecen, por un lado, los personajes de los criminales y, por el otro, los narradores y el lector, es determinante en la estructuración de estos textos ya que se presentan las historias desde el punto de vista de la exposición de una experiencia teóricamente foránea al lector. En el discurso explicativo de la realidad del sicario que caracteriza a estas novelas, la ausencia de arrepentimiento por parte de los asesinos protagonistas cuestiona el razonamiento moral y ético de la sociedad que los produce. De esta forma, el matiz particular que en estas novelas toma la inexistencia de remordimientos, es el aspecto que marca la especificidad genérica de la sicaresca. En el juego de espejos que construyen estas obras con los conceptos de la víctima y el victimario, el espacio vacío que deja la falta de contrición y que se espera lo llene el intercambio simbólico de una disculpa, pone en evidencia la realidad yuxtapuesta e irreconciliable de las dos caras de la ciudad. Porque la sicaresca construye la posibilidad de un precario diálogo entre personajes de las comunas y de la ciudad, las víctimas esperan de sus agresores una exculpación, y el hecho de que ésta nunca aparezca hace visible la confusión de identidades que plantean estas novelas. ¿Quién es quién? ¿Quién pide perdón a quién? 
Como ha señalado Nicholas Tavuchis, el pedir perdón es una forma de autocastigo que impone la necesidad de recontar y revivir los actos que han arriesgado la permanencia del sujeto en una determinada comunidad moral (8). Sin embargo, en estos textos, la realidad de los criminales se construye a partir de la conciencia de la no pertenencia a la comunidad moral de los habitantes de la ciudad legitimada. Es decir, los valores y las reglas quebrantadas no tienen para el sicario ninguna connotación ética. Por esa razón, en la búsqueda de la declaración del resquemor del criminal, el lector descubre que tanto el proceso de reconocimiento de las faltas contra la comunidad moral hegemónica como la petición de absolución por los crímenes, funcionarían como las ejecuciones públicas de la Francia dieciochesca de las que habla Foucault: no para reestablecer la justicia sino para reactivar el poder (49). En este caso, el poder del sector que se siente víctima de los sicarios. La ausencia de arrepentimiento, y en consecuencia de la disculpa, se presenta en estas novelas no sólo como la expresión muda de la violencia, sino que también define la condición ratificadora de la concepción del espacio urbano como uno dividido en dos realidades. Cada una de ellas, creadora de sus propias reglas de membresía.

El drama principal del protagonista de La virgen de los sicarios es, precisamente, la conciencia de que el espacio social de la ciudad está compuesto por dos universos culturales incompatibles. ${ }^{7}$ El intento por fusionar las distintas realidades, a través de la recreación de la alegoría (re)fundacional del amor entre representantes de la comuna y el valle, fracasa doblemente. Por un lado, por el hecho de ser una relación homosexual y alejarse del patrón "reproductivo" tradicional y, por el otro, porque en los valores sobre los que se intenta definir la pertenencia a uno de esos universos se descubre la voz irreconciliable de la violencia social. ${ }^{8}$ En esta novela, el narrador en primera persona, cuyo nombre coincide con el del autor, nos cuenta una particular historia personal centrada en sus relaciones amorosas con dos jóvenes sicarios. Se trata de Alexis y Wílmar quienes mueren víctimas de la violencia de la que son fruto: Wílmar mata a Alexis en venganza por la muerte de su hermano para posteriormente convertirse en el blanco de otro sicario. En el intento de localizar responsabilidades, el personaje principal y narrador progresivamente va abandonando la posición asumida de vocero de "la gente decente” para convertirse en el autor intelectual de los crímenes que cometen sus amantes. El narrador inicialmente se presenta como salvaguarda de las leyes creadas para mantener la separación de los espacios de acción de los habitantes de las comunas y el de los de la clase media y alta. Por su supuesta condición de crítico social, él intenta funcionar como el puente entre esos dos mundos. Sin embargo, aunque Fernando se vea a sí mismo como la memoria y conciencia del país, como traductor de jergas, sociólogo, antropólogo y etnólogo; es decir, como el expositor ante el lector de un particular análisis de la cara temida de Medellín, no logra

\footnotetext{
${ }^{7}$ Vale la pena acotar que esta novela, además de haber sido traducida a varias lenguas, fue llevada al cine por el director Barbert Schroeder, con guión del propio autor.

${ }^{8}$ Francine Masiello también destaca el aspecto dual de la estructura de la novela pero lo hace a partir de la concepción del tiempo que tienen los personajes. Sin embargo, aunque dicha noción del tiempo sea diferente para cada uno de ellos, revela la misma idea de un futuro negado. Así indica Masiello: "Con un futuro vacío para los delincuentes, y para el intelectual [el narrador], un pasado que evoca la bancarrota de la nostalgia, todos los personajes representados en la obra de Vallejo atestiguan un presente estático sin esperanza de un proyecto comunitario" (101).
} 
convertirse en el lazo efectivo para la unión de esos dos ámbitos. Esa posición intermedia que intenta abrazar el narrador, no se concreta debido a su insistencia por destacar una excelencia moral predefinida por el hecho de ser de la siguiente manera un ente ajeno al mundo de las comunas. Fernando describe el espacio citadino y sus actores a partir del prejuicio geográfico que, en general, caracteriza la experiencia urbana latinoamericana:

Bajo un solo nombre Medellín son dos ciudades: la de abajo, intemporal, en el valle; y la de arriba en las montañas rodeándola. Es el abrazo de Judas. Esas barriadas circundantes levantadas sobre las laderas de las montañas son las comunas, la chispa y leña que mantienen encendido el fogón del matadero. La ciudad de abajo nunca sube a la de arriba pero lo contrario sí: los de arriba bajan, a vagar, a robar, a atracar, a matar. (82)

Comprobamos que la concepción del espacio como un área dividida entre las víctimas de abajo y los victimarios de arriba, participa de la trampa de las identidades sociales impuestas. El hecho de que los personajes vivan la ciudad como el escenario de una violencia producto de la discriminación social, provoca que a partir del diálogo al que los obliga el momento de encuentro, se descubran a sí mismos como reflejo del otro. Víctimas se revelan como victimarios y viceversa. Es así entonces como el discurso de Fernando, desde el comienzo, levanta sospechas en cuanto al valor de su "honorabilidad", y éstas se concretan cuando el lector reconoce en las palabras del gramático el principal agente de la violencia en la novela. La transformación de Fernando ante el lector comienza cuando incorpora el habla de los sicarios en su discurso y termina cuando su insensibilidad hacia la muerte es tal, que el hecho de que su primer amante haya sido asesinado por el segundo hace obvia su concepción de los jóvenes de las comunas como sujetos desechables. De este modo, al confrontar al lector con el peso de la identidad social asignada a los jóvenes de las barriadas pobres, toma lugar la expresión de la tensión entre un sujeto que se asume a sí mismo a merced de la criminalidad urbana pero que progresivamente se revela responsable de la violencia que tanto teme. ${ }^{9}$

El elemento que particulariza la narración de Vallejo, y que es el aspecto que considero la marca distintiva del género que él bautiza, es el papel que dentro de la novela juega la carencia total de arrepentimiento frente a la violencia causada. El relato del esquizofrénico vagar de Fernando por las calles de Medellín, haciendo que su amante de turno se deshaga literalmente de todo aquel que moleste su sensibilidad, no se presenta como confesión sino como una acomodada relación de acontecimientos en los que destaca el hecho de que él "solamente" tomó parte como testigo. Todas sus víctimas son ajusticiadas en manos de los sicarios, pero está claro que el autor intelectual es el narrador que reclama, a través de la violencia de su discurso, el control sobre la ciudad que su clase siente perdido. Fernando no acepta su responsabilidad como partícipe activo del caos que

\footnotetext{
${ }^{9}$ Susana Rotker, aunque se refiere con mayor énfasis a la experiencia caraqueña, señala un aspecto que obviamente puede aplicarse al caso de Medellín. Rotker indica que "en sociedades donde se vive con esta sensación de injusticia, tal vez haya que preguntarse sobre el efecto de los lazos de sociabilidad y cómo funcionan los vínculos de grupo sobre los individuos. O acaso haya que replantearse la noción de qué es un ciudadano: ya los parámetros diseñados o soñados en las constituciones escritas, luego de las guerras de independencia, no funcionan” (222).
} 
lo rodea, al igual que los sicarios no se sienten culpables por aquellos a quienes matan al ser contratados. La culpa siempre es de otros. Fernando explica su inocencia ante uno de los crímenes de Alexis de la siguiente manera:

¿De quién es el pecado de la muerte del hippie? ¿De Alexis? ¿Mío? (...) Que no lo quería, confieso. ¿Pero que lo mandé a matar? ¡Nunca! Jamás de los jamases. Jamás le dije a Alexis: "Quebráme a este”. Lo que yo dije y ustedes son testigos fue: "Lo quisiera matar" y se lo dije al viento; mi pecado, si alguno, se quedó en el que quisiera”. (33)

En el momento en que Fernando se apropia de la violencia irracional que caracteriza a los sicarios, los prejuicios que fundamentan su discurso dejan de ser posiciones ideológicamente inofensivas para convertirse en las verdaderas armas que afectan la paz social. Es así como su discurso lo va formando, paradójicamente, la ausencia de arrepentimiento. Esta carencia tiene un papel principal en la novela ya que, como han señalado desde Durkheim hasta Foucault, el ritual del arrepentimiento del criminal tiene como función reforzar los valores sobre los que se sostiene una determinada comunidad (Wuthnow 180). En Fernando no hay ni resquemor ni remordimiento porque dichos valores han perdido su valor semántico, no significan nada. De esta forma, la ausencia de contrición por parte del criminal que personifica el narrador, no sólo funciona como espejo en el que se miran los sujetos cuya superioridad moral proviene de la posición geográfica que ocupan con respecto de las zonas marginales, sino que también mina los pilares éticos de una sociedad que abona el terreno del miedo y la violencia como valores comunales.

Otro caso interesante en el que la expresión sin remordimientos del delito se presenta como la voz de la otra cara de la ciudad lo hallamos en Rosario Tijeras de Jorge Franco. En esta novela encontramos la crudeza del recuento de la vida criminal a través de las aventuras del personaje femenino que sirve de título a la novela. Todo comienza cuando en los corredores de un hospital, conocemos a Antonio, joven de una familia de "gente bien,” esperando recibir noticias sobre el estado de salud de Rosario (quien ha llegado acribillada a balazos), y reflexionando sobre lo que ha significado para él enamorarse platónicamente de esa joven prostituta y asesina por contrato.

En la novela de Franco, la visión dual de la ciudad característica de la sicaresca se expresa desde la perspectiva del deseo prohibido. El obstáculo que impide que se concrete la relación amorosa entre la joven de las comunas y Emilio, el mejor amigo del narrador, es la diferencia de clase determinada por el lugar de origen. Por otra parte, y al igual que en La Virgen de los sicarios, la construcción de los personajes se sostiene principalmente sobre la posicionalidad geográfica que ocupan en la ciudad, y ello lo deja claro Antonio cuando introduce el carácter agresivo de Rosario como consecuencia de su procedencia:

Estuvo metida con los duros que ahora están en la cárcel, con los duros de los duros, los que persiguieron mucho tiempo, por los que pidieron recompensas, los que se entregaron y después se volaron, y con muchos que andan "cargando tierra con el pecho". Ellos la bajaron de su comuna, le mostraron las bellezas que hace la plata, cómo viven los ricos, cómo se consigue lo que uno quiere, sin excepción, porque todo se puede conseguir si uno quiere. La trajeron hasta donde nosotros, nos la acercaron, nos la mostraron como diciendo miren culicagados que nosotros también tenemos mujeres buenas y más 
arrechas que las de ustedes, y ella ni corta ni perezosa se dejó mostrar, sabía quiénes éramos, la gente bien, los buenos del paseo... (22)

La violencia que encarna Rosario se presenta dentro del aura de exotismo que cubre a cualquier sujeto proveniente de un universo desconocido. Su encanto lo define su condición de extranjera dentro de su propia ciudad, aspecto que pone de relieve la muralla que separa las realidades del narrador y la de la protagonista.

La idea, entonces, de un "nosotros/gente bien/víctimas” frente a un “ellos/delincuentes/ victimarios” es, al igual que en la novela de Vallejo, nuevamente cuestionada, pero esta vez a partir de la noción de la culpa. La muerte de Rosario, motivo que inicia la novela, es el desembarcadero desde el cual parte el viaje de reconocimiento interior de Antonio, quien en el transcurso de su recorrido se descubre cómplice y, por lo tanto, victimario de la realidad que ha acabado con la vida de la joven asesina. Antonio, como relator testigo del momento en que los mundos de Rosario y Emilio establecen el efímero diálogo, en su papel de amigo y enamorado platónico de la asesina, recorre los caminos de la culpa al que lo enfrenta el discurso impenitente y, por ello, acusador, de Rosario. De esta forma, si en La virgen de los sicarios la empatía entre lector y narrador queda saboteada por la violencia del discurso de este último, la novela de Franco se esfuerza en recuperar esta empatía pero a través del proceso de reconocimiento de una culpa ignorada por el narrador. Antonio, al presentar la realidad de Rosario, ofrece la descripción de un mundo agotado por una violencia de la que él, en parte, se siente responsable:

En la soledad de los pasillos siento la angustiosa soledad de Rosario en este mundo, sin una identidad que la respalde, tan distinta a nosotros que podemos escarbar nuestro pasado hasta el último rincón del mundo, con apellidos que producen pruebas de aceptación y hasta perdón por nuestros crímenes. (13)

De esta forma, Antonio ofrece un relato que, al tratar de dar una explicación al porqué de Rosario Tijeras, va intensificando la violencia y con ello la culpa que genera reconocerse como victimario. La tragedia del narrador es que sólo es capaz de asumir su responsabilidad cuando tiene lugar la expresión máxima de la violencia: el asesinato del objeto de su deseo.

Lo interesante de la propuesta de Franco es que su narrador, al irrumpir en el mundo desconocido al que lo arrastra su pasión por Rosario, es seducido por el relato impertérrito de la sicaria. El texto crudo de la historia de su vida es el arma que emplea esta suerte de femme fatal poco sofisticada, para llevar al narrador a conocer los mecanismos de funcionamiento de un ámbito indicador de culpas, y en el que no caben los arrepentimientos. ${ }^{10}$

${ }^{10}$ Mary-Ann Doane asocia la representación de la femme fatale al miedo a la castración. Doane indica: "Her textual eradication [la de la femme fatale] involves a desperate reassertion of control on the part of the threatened male subject. Hence, it would be a mistake to see her as some kind of heroine of modernity” (2). En la novela de Franco esta ansiedad puede leerse no sólo a través del final del personaje principal, sino incluso en el origen de su apodo. Rosario castra con unas tijeras a quien la viola a los trece años (37-38). Además, el narrador, después de su única relación sexual con Rosario y de que ésta lo rechace, lo confirma: "Las tijeras son tu chimba [vagina], Rosario Tijeras" (191). 
La novela es explícita en su propósito de mostrar los orígenes de la violencia de Rosario $\mathrm{y}$, sin lugar a dudas, presenta a la protagonista desde una óptica que busca hacer inteligible la incontrolable carga de violencia que la ahoga. El padre fue siempre una figura inexistente; fue violada varias veces (la primera a los 8 años y por uno de los amantes de la madre), y como posible escape a su miseria trabajó como prostituta y sicaria para los capos del narcotráfico. En la reconstrucción discursiva de la lucha por escapar de esa realidad la contrición no ocupa ningún lugar. Las reglas quebrantadas para lograr ese escape carecen de valor en el universo de las comunas, puesto que las únicas que existen son las de la lucha por la supervivencia. En Rosario Tijeras matar por contrato es la respuesta radical de las víctimas de la violencia social. La ausencia de remordimientos en el discurso de la sicaria se contrapone al peso que estos tienen en el discurso del narrador. Todos sabían que cuando Rosario mataba, desaparecía y engordaba. El miedo y la culpa quedaban escritos en las estrías de sus piernas y abdomen: "Yo he sido gorda muchas veces” (17), explicaba fríamente. Pero las marcas de su cuerpo no hacen mella en el relato de su historia. Sin embargo, el narrador, por su condición de personificador de los habitantes del valle, reconoce la culpa, acepta la responsabilidad e intenta, a partir de sus recuerdos, articular su arrepentimiento por la tácita participación en la construcción del mundo en el cual le tocó vivir y morir a Rosario Tijeras.

Esas mismas nociones de culpa y arrepentimiento vistas a la luz de la proyección de la doble cara de la ciudad en la identidad del sujeto urbano adquieren una interesante perspectiva en la novela Sangre ajena de Arturo Alape. En esta obra, el ex-sicario Ramón Chatarra relata su vida a un interlocutor, alter ego del autor, quien se propone escribir una novela con el material de esas conversaciones. La historia que nos cuenta este joven se inicia con su precoz iniciación en el mundo del crimen organizado y termina con la llegada a una adultez inesperada puesto que su destino de sicario era el de morir joven. A los ocho años, junto a su hermano Nelson, abandona su familia en Bogotá para irse a Medellín y cambiar el escenario de su miseria. Ocho meses más tarde, ya ha sido entrenado y contratado para "trabajar”, es decir: para robar y matar. A los 19 años, cuando rememora para el supuesto novelista su historia personal, lo encontramos de regreso en Bogotá, retirado del sicariato y dedicado a la recolección de basura para mantener a su esposa y a su hija.

Sangre ajena, por su condición de novela seudotestimonial, se asocia a un género que, como señala John Beverley, tradicionalmente ha intentado establecer una relación directa con el lector sostenida en la explicación de las circunstancias sociales o políticas que el narrador, un sujeto perteneciente al grupo de los considerados "sin voz", quiere que el lector conozca para apelar así a su sentido ético y de justicia con el fin de acercarlo a la causa que defiende o a la que pertenece (31). ${ }^{11}$ Apoyado en las licencias de la ficción, la propuesta de Alape ignora, desde las primeras líneas de la novela, la validez de esa condición persuasiva del género testimonial. Al comienzo de la obra nuestro locutor declara: "No estoy hablando de arrepentimientos en este instante en que trato de prender

\footnotetext{
${ }^{11} \mathrm{Al}$ referirme al juego que Sangre ajena plantea con el género testimonial, me apoyo en la aserción de Elzbieta Sklodowska, quien define el testimonio partiendo del hecho de que "no se trata de una modalidad discursiva nítidamente escindida, así que textos aducidos como testimoniales van desde autobiografías hasta novelas pseudofactuales” (179).
} 
una llama a mis recuerdos. El arrepentimiento y la culpa son pura mierda, en la cual uno se va hundiendo, como si fuera arena movediza, ahogándose hasta dejar de respirar y perder la fuerza de vivir” (13). El carácter retador de esta sentencia de Ramón Chatarra define lo que será el contrato de lectura de Sangre ajena: una constante lucha por decidir si se condena o si se perdona al protagonista. Y hablamos de lucha porque el interlocutor, sujeto que, teóricamente, en un texto testimonial sólo es una sombra organizadora del material y no portadora de juicios de valor, ignora esa otra regla básica, y en el inicio de cada sección de la novela nos ofrece una visión desgarradora de la realidad que rodea al ex-sicario. Al mismo tiempo, el supuesto novelista se esfuerza por presentar un retrato afable del joven a quien se describe, desde el inicio, como víctima de la sociedad en la que vive. Sangre ajena se construye así sobre dos voces: una que cuenta el horror del crimen sin arrepentimientos y otra que, solapadamente, y como en un intento de expiar culpas, trata de explicarlo. Consecuentemente, y siguiendo el patrón del sicario literario, la ausencia de contrición en la historia de Ramón Chatarra se presenta como la conciencia del que posee una identidad social definida por una sociedad que lo predestina, por venir de las comunas, a ser criminal. Ramón Chatarra asume esa identidad tal y como se le ha impuesto: demonizada, inhumana, irreal, desechable. ¿Por qué arrepentirse entonces de lo que los que no conocen ni han vivido nunca en las comunas lo han obligado a ser?

Al discurso de Ramón Chatarra no le da forma una intención explicativa que pueda justificar sus acciones pasadas. Las referencias al alcoholismo de su padre, al abuso físico de éste hacia su madre, a las condiciones de pobreza extrema en las que vivió, etc., no son nunca expresamente mencionadas en su discurso como los motivos que lo empujaron a seguir la vida del sicariato. La razón que nos ofrece es el inmenso amor que sintió por su hermano, y ese sentimiento lo hizo seguirlo por los destierros del crimen callando sus miedos y sus dudas. En consecuencia, el lector se pregunta: ¿qué espera Ramón Chatarra del recuento de su vida? La respuesta es sencilla: nada. Y no espera nada de nadie ya que por no cumplir con la condición "desechable" de los sicarios y no morir joven, vive una vida que, como la de los habitantes del mundo de La Virgen de los sicarios, es la de los muertos en vida.

De esta manera, y trayendo nuevamente a colación a John Beverley, si la efectividad del texto testimonial se fundamenta en la intención del narrador; es decir, en la urgencia por comunicar la situación de represión, de pobreza, de subalternidad, etc., que permita al lector no sólo enterarse de las condiciones de vida -por lo general ajenas a su contextosino también entenderlas, la historia de Ramón Chatarra no puede decirse que se esfuerza en lograrlo. La intencionalidad reparadora se manifiesta en su interlocutor quien es, al fin y al cabo, el sujeto que ha seleccionado el material del texto que el lector tiene frente a sus ojos, y es el único puente entre el mundo del sicariato y el lector. Así, y como tratando de reparar daños, el interlocutor lleva a cabo una desesperada búsqueda por entender los motivos de las acciones del sicario a través de su continuo señalamiento al contexto que lo forjó. Como resultado, las voces del sicario y su interlocutor se interceptan en la directa acusación al lector. La indiferencia de este último, ante los ojos del narrador y del interlocutor/transcriptor, lo revela como el responsable de la realidad que le ha tocado vivir a Ramón Chatarra. Pero como todo punto de intersección es, a un tiempo, ineludible y breve. Y es que si el protagonista veladamente acusa al lector lo hace a través de su 
percepción del interlocutor. No en vano, antes de entrar de lleno en el recuento de su historia, nuestro ex-sicario le dice a su escucha, representante de los que no viven en las comunas: “Usted toreó las llamas de mis recuerdos. Entonces saque papel y escriba, y ojalá no le tiemblen la conciencia y el entendimiento” (15). El final de la novela revela que el limitado acuerdo entre las dos voces no puede mantenerse porque para Ramón Chatarra, su interlocutor es el sujeto que pertenece a la clase que impone las condiciones materiales de ciudadanía que lo empujaron por la vía del crimen. Sin embargo, para ese interlocutor, el interés por entender las razones que forjaron la historia del sicario lo separa de ese grupo apático con el que Ramón lo identifica. La novela termina así con la visión de Ramón Chatarra, como pagando por una terrible penitencia, recogiendo la basura de la ciudad que lo forjó.

Podemos concluir, a partir de los ejemplos ofrecidos, que la nueva novela colombiana que escoge el tema de la violencia que genera el narcotráfico -y que los escritores han bautizado, medio en broma, medio en serio, la "sicaresca”- define su condición genérica a partir de la noción de que la violencia última del sicario reside en la ausencia de arrepentimiento. Esta caracterización de la representación discursiva de los asesinos por contrato es, además, el elemento que particulariza la violencia que presentan estas novelas. Sin duda alguna, es también el factor que explica el rechazo que estas narraciones han generado por parte de otros autores y de algunos críticos y lectores..$^{12} \mathrm{Y}$ es que, por medio de la construcción de un sujeto proveniente de las zonas marginales, lleno de una incontenible carga de violencia y que nunca llega a expresar aflicción por los crímenes cometidos, el lector se ve obligado a buscar la explicación que da origen a esa violencia para, en la indagación, descubrirse él mismo como el promotor del horror del cual se siente víctima. De esta forma, estas novelas al recrear al sicario no sólo como un sujeto marginado social y geográficamente, sino también marginable por sus acciones y falta de contrición, se construyen sobre una estructura narrativa en la cual la representación del crimen se convierte en acusación directa al sujeto que vive del otro lado de la ciudad, fuera de los límites de las barriadas. No obstante, para que la estructura de esa recriminación se sostenga, es necesario que las novelas cuenten con un personaje representante del mundo al que anhelan acceder quienes viven en las comunas. Dicho personaje puede hacer las veces de puente entre los dos mundos sólo porque ha aceptado su complicidad en el juego de la violencia. Es ese el caso de Fernando en La virgen de los sicarios, de Antonio en Rosario Tijeras y del interlocutor en Sangre ajena.

La representación literaria del sicario intenta funcionar como lente corrector a las miradas miópicas que se asientan sobre el paisaje urbano y el lugar de actuación predeterminado que deben ocupar sus actores. El sicario como motivo encarna necesariamente la conciencia de la doble perspectiva geográfica que caracteriza a la ciudad. De esta manera, ese lente corrector del que hablamos se apoya en un discurso caracterizado por la crudeza y frialdad que el lector descubre en estos jóvenes asesinos. Sujetos que permanecen irreductibles frente a la exigencia de arrepentimientos que

\footnotetext{
${ }^{12}$ Héctor Abad Faciolince se ha declarado desafecto al motivo del sicario: "No tengo interés por ser mínimamente cómplice, condescendiente con estos ángeles de la muerte. La peste de la ciudad yo la padezco, pero no la canto” (“Oponer las palabras...”).
} 
simbólicamente impone la membresía a una comunidad nacional que, como la colombiana, nunca ha dejado de imaginarse distinta.

\section{BiBLIOGRAFÍA}

Alape, Arturo. Sangre ajena. Bogotá: Seix Barral, 2002.

Beverley, John. Testimonio: On the Politics of Truth. Minneapolis/London: University of Minnesota Press, 2004.

Bowden, Mark. Killing Pablo. The Hunt for the World's Greatest Outlaw. New York: Penguin Books, 2002.

Doane, Mary-Ann. Femmes Fatales: Feminism, Film Theory, Psychoanalysis. New York: Routledge, 1991.

Dunn, Peter. Spanish Picaresque Fiction. A New Literary History. Ithaca: Cornell University Press, 1993.

“Fin de una tragedia que cambió al país”. Editorial. Semana 3 de enero de 1994 <http:// semana2.terra.com.co/archivo/articulosView.jsp?id=54691> (11 de enero de 2005).

Foucault, Michel. Discipline and Punish. The Birth of the Prision. New York: Vintage Books, 1995.

Franco, Jean. The Decline and Fall of the Lettered City: Latin America in the Cold War. Cambridge, MA: Harvard University Press, 2002.

Franco, Jorge. Rosario Tijeras. Bogotá: Norma Editorial, 1999.

García Canclini, Néstor. Consumers and Citizens. Globalization and Multicultural Conflicts. Geroge Yúdice, trad. Minneapolis: University of Minessota Press, 2001.

Giraldo, Carlos Alberto, ed. Rasgando velos. Ensayos sobre la violencia en Medellín. Medellín: Editorial de la Universidad de Antoquia, 1993.

Masiello, Francine. “Milagros y modernidad”. Fronteras de la modernidad en América Latina. Hermann Herlinghaus y Mabel Moraña, eds. Pittsburgh: Instituto Internacional de Literatura Iberoamericana, 2002.

“Oponer las palabras a la muerte es mi apuesta literaria”. La Jornada 27 de mayo de 1999. <http://www.jornada.unam.mx/1999/may99/990527/cul-oponer.html> (11 de enero de 2005).

"Premio Alfaguara por su novela Delirio. Laura Restrepo: 'Me interesa incidir en la realidad de Colombia, mi país'.” UOL 24 de febrero de $2004 . \quad<$ http:// www.uolsinectis.com.ar/biblioteca/html/notas/200402240245/> (11 de enero de 2005).

Prieto Osorno, Alexander. Los sicarios de Medellín. Bogotá: Consorcio de Edicones Capriles, 1999.

Rotker, Susana, ed. Ciudadanías del miedo. Caracas: Nueva Sociedad, 2001.

Salazar, Alonso, ed. La génesis de los invisibles. Historias de la segunda fundación de Medellín. Bogotá: Ediciones Antropos, 1996.

, ed. En qué momento se jodió Medellín. Bogotá: Editorial Oveja Negra: 1991.

Sklodowska, Elzbieta. Testimonio Hispano-Americano. Historia, teoría, poética. New Cork: Peter Lang, 1992. 
Tavuchis, Nicholas. Mea Culpa. A Sociology of Apology and Reconciliation. Stanford: Standford University Press, 1991.

Vallejo, Fernando. La virgen de los sicarios. Bogotá: Alfaguara, 1994.

Von der Walde, Erna. "La novela de sicarios y la violencia en Colombia”. Iberoamericana 3 (2001): 27-40.

Wuthnow, Robert. "Repentance in Criminal Procedure: The Ritual Affirmation of Community”. Repentance. A Comparative Perspective. Amitai Etzioni y David Carney, eds. Lanhan: Rowman and LittleField Publishers, 1997. 
